Article

\title{
Evaluation of Serum Serotonin as a Biomarker for Myocardial Infarction and Ischemia/Reperfusion Injury
}

\author{
Marina Rieder 1,2, , Rosmarie Laumann ${ }^{1,2}$, Thilo Witsch ${ }^{1,2}$, Nancy Schanze ${ }^{1,2}$, Lukas Heger ${ }^{1,2}$, \\ Christoph B. Olivier 1,2 (D), Constantin von zur Muehlen 1,2, Christoph Bode 1,2, Ingo Ahrens 1,2,3, \\ Achim Lother 1,2,4 , Daniel Duerschmied ${ }^{1,2}$ and Marcus Hortmann 1,2 \\ 1 Department of Medicine III (Interdisciplinary Medical Intensive Care), Medical Center, Faculty of Medicine, \\ University of Freiburg, 79085 Freiburg, Germany; rosmarie.laumann@uniklinik-freiburg.de (R.L.); \\ thilo.witsch@universitaets-herzzentrum.de (T.W.); nancy.schanze@universitaets-herzzentrum.de (N.S.); \\ lukas.heger@universitaets-herzzentrum.de (L.H.); Christoph.Olivier@universitaets-herzzentrum.de (C.B.O.); \\ constantin.vonzurmuehlen@universitaets-herzzentrum.de (C.v.z.M.); \\ christoph.bode@universitaets-herzzentrum.de (C.B.); kardiologie@severinskloesterchen.de (I.A.); \\ achim.lother@universitaets-herzzentrum.de (A.L.); \\ daniel.duerschmied@universitaets-herzzentrum.de (D.D.); \\ marcus.hortmann@universitaets-herzzentrum.de (M.H.) \\ 2 Department of Cardiology and Angiology I, Heart Center Freiburg University, Faculty of Medicine, \\ University of Freiburg, 79106 Freiburg, Germany \\ 3 Department of Cardiology and Medical Intensive Care, Augustinerinnen Hospital, Academic Teaching \\ Hospital, University of Cologne, 50923 Köln, Germany \\ 4 Institute of Experimental and Clinical Pharmacology and Toxicology, Faculty of Medicine, \\ University of Freiburg, 79104 Freiburg, Germany \\ * Correspondence: marina.baeuml@universitaets-herzzentrum.de; Tel.: +49-761-270-34010
}

Received: 30 July 2020; Accepted: 10 September 2020; Published: 13 September 2020

\begin{abstract}
Background: Activated platelets release serotonin during acute myocardial infarction (AMI), aggravating myocardial damage and ischemia/reperfusion (I/R) injury. However, serum serotonin and its potential role as a biomarker for myocardial infarction and $\mathrm{I} / \mathrm{R}$ injury have not been studied so far. Methods: In this investigator-initiated pilot study, we examined 38 patients with ST-segment myocardial infarction (STEMI). We determined serum serotonin levels prior to percutaneous coronary intervention and 8, 16, and $24 \mathrm{~h}$ afterwards. We studied whether serum serotonin was associated with I/R injury assessed by ECG analysis and by analysis of TIMI myocardial perfusion grade (TMP) and myocardial blush grade (MGB). Serum serotonin levels were compared to an age-matched control group consisting of patients admitted to the emergency department for any other reason than STEMI. Results: Serum serotonin levels were not elevated in the myocardial infarction group compared to the control cohort and they did not show any timeline kinetics after STEMI. They were not associated with the severity of coronary artery disease, the outcome of coronary angiography, the extent of $I / R$ injury, or the degree of heart failure. Conclusions: Serum serotonin is not suitable as a biomarker after myocardial infarction and in the assessment of $\mathrm{I} / \mathrm{R}$ injury.
\end{abstract}

Keywords: serotonin; STEMI; ischemia/reperfusion injury

\section{Introduction}

Despite therapeutic advances in recent decades, coronary artery disease (CAD) and its sequela acute myocardial infarction (AMI) are still a major cause of morbidity and mortality worldwide [1,2]. In AMI, early recognition and initiation of reperfusion therapy are crucial to limit myocardial ischemia 
and infarct size and thereby reduce mortality and post-infarct complications such as heart failure $[3,4]$. Up to $25 \%$ of patients with urgent need of primary percutaneous coronary intervention lack typical ST-segment elevation on a 12-lead electrocardiogram (ECG) as an indication of coronary occlusion or critical stenosis [5]. Therefore, a combination of ECG analysis and biomarker tests is the gold standard for the diagnosis of AMI [6]. Currently, elevated high-sensitivity cardiac troponins (hs-cTn) are required for the diagnosis of AMI [6]. However, the specificity of hs-cTn for acute myocardial infarction is limited [7] and they are frequently elevated in acute myocardial injury of non-ischemic origin $[6,8,9]$. Moreover, troponins can be chronically raised in patients with congestive heart failure or chronic kidney disease [6,7]. Furthermore, there is a lack of established biomarkers for ischemia reperfusion (IR) injury [10]. IR injury occurs when reinitiated blood flow through a percutaneous coronary intervention (PCI) causes additional cardiomyocyte death by activating a complex cascade of cellular myocardial and coronary microvascular reactions [10,11].

Finding novel biomarkers for AMI and IR has therefore become an important focus of medical research.

In recent years, platelet serotonin (5-hydroxytryptamine (5-HT)) has come into focus as an important factor in AMI [12]. The effects mediated by 5-HT are very complex, as it acts as both a peripheral hormone and a neurotransmitter. Central 5-HT is synthesized by tryptophan hydroxylase 2 in the brainstem. It is separated from the peripheral 5-HT by the blood/brain barrier and is reported to regulate mood, appetite, and circadian rhythm. Disturbances in the central serotonergic system lead to psychiatric diseases like depression $[13,14]$. Tryptophan hydroxylase 2 is also expressed by the enteric nervous system in the periphery [15]. However, most peripheral 5-HT is synthetized by tryptophan hydroxylase 1 in the gut, with platelets being its main circulating reservoir [13,16]. In peripheral tissues, 5-HT is involved in a broad variety of functions, including regulation of vascular tone [17], hemostasis [18], and immune responses [19-21].

5-HT was reported to be an important mediator in AMI and IR: The platelet-stimulating microenvironment in AMI leads to an activation of platelets with the consecutive release of serotonin [22]. This elevation in 5-HT levels leads to a constriction of coronary smooth muscle cells, worsening myocardial damage [23]. Moreover, platelet serotonin induces neutrophil degranulation after MI, further aggravating myocardial damage by contributing to increased IR [12]. Consequently, the depletion of platelet serotonin stores improves the outcome after AMI [12,24].

Previous animal and human studies described an elevation of 5-HT after AMI and an association with I/R injury $[12,25]$. In humans, elevated 5-HT levels were found in aspirates from the culprit coronary artery of patients with acute myocardial infarction [26].

In our study, we aimed to investigate the diagnostic potential of serum 5-HT as a biomarker in $\mathrm{AMI}$ and to determine whether it can be used to predict IR.

\section{Materials and Methods}

\subsection{Patient Population}

This investigator-initiated pilot single-center study was conducted at the University Heart Center, Freiburg between March 2017 and May 2018. The protocol of this study conforms to the ethical guidelines of the 1975 Declaration of Helsinki and was approved by the institutional ethical committee of the University of Freiburg (EK 137/16). Written informed consent was obtained from all participants prior to inclusion.

Patients admitted to our department due to ST-segment myocardial infarction (STEMI) with the objective of immediate restoration of blood flow by coronary intervention were screened for eligibility. Exclusion criteria were sepsis, life-limiting oncologic or hematological diseases, or the inability to provide informed consent. The final study population consisted of 38 patients. None of the patients reported the intake of serotonin reuptake inhibitors (SSRIs) or any other psychiatric medication. 
Age-matched patients admitted to the department of emergency medicine of the University Medical Center-University of Freiburg for any other reason than STEMI served as the control group. The collection of serum from these patients was approved by the institutional ethical committee of the University of Freiburg (EK 153/20). Patients were recruited between March 2020 and June 2020, and again, written informed consent was obtained from all participants prior to inclusion. Only patients without intake of antiplatelet therapy such as, e.g., ASS, clopidogrel, ticagrelor, or prasugrel, were included in the analysis for this manuscript.

\subsection{Primary Percutaneous Coronary Intervention (PCI)}

PCI in the STEMI group was performed according to the European Society of Cardiology (ESC) guidelines [27]. Prior to intervention, unfractioned heparin (5000IE) was administered. Moreover, all STEMI patients received aspirin (minimum of $250 \mathrm{mg}$ ) and either prasugrel $60 \mathrm{mg}$ or ticagrelor $180 \mathrm{mg}$. None of our patients received sarpogrelate, a 5HT2A antagonist. We analyzed the thrombolysis in myocardial infarction (TIMI) grade prior and post coronary angiography to assess the success of the PCI [28].

\subsection{Blood Collection}

In the STEMI group, venous blood was collected into serum tubes (Sarstedt, Nümbrecht, Germany) prior to coronary angiography and 8,16 and $24 \mathrm{~h}$ after intervention. After collection, the blood was incubated at room temperature for $20 \mathrm{~min}$ and then centrifuged $\left(1500 \times g, 20{ }^{\circ} \mathrm{C}\right)$. The resulting supernatant (serum) was aliquoted and stored at $-20^{\circ} \mathrm{C}$.

Serum samples from the control group were obtained immediately after admission to the emergency department.

\subsection{Patient Characteristics/Laboratory Findings}

Patient characteristics were obtained from the electronic health record. Laboratory values such as C-reactive protein (CRP), serum creatinine, serum urea (BUN), creatine kinase (CK), myoglobin, brain natriuretic peptide (pro-BNP), and troponin were assessed and obtained from the electronic health record.

\subsection{Ischemia/Reperfusion Injury}

In the STEMI group, ECGs from 17 patients were analyzed before and after (mean $41 \pm 11 \mathrm{~min}$ ) PCI. A decrease in ST-elevation by a minimum of $70 \%$ was set as the cut-off for a patient to be considered adequately reperfused [29]. Patients could then be subdivided into adequately reperfused or reperfusion injury groups according to this ECG criterion [29-32]. For the assessment of I/R injury, we did not only use the surrogate parameter of ST-elevation resolution, but also determined the visually direct markers, TIMI myocardial perfusion grade (TMP) and the mycoardial blush grade (MGB) [33,34]. Analysis of coronary angiography was conducted by a blinded investigator.

\subsection{Determination of Serum Serotonin Levels}

Serotonin was analyzed in the serum samples using an enzymatic immunoassay kit (Serotonin

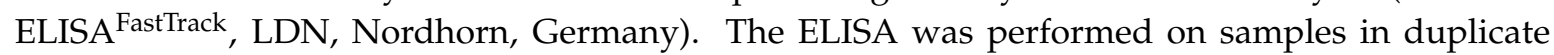
following the manufacturer's instructions. All samples and standards were analyzed on a microplate reader set at $450 \mathrm{~nm}$.

According to the data sheet, the detection range of the ELISA was $15-2500 \mathrm{ng} / \mathrm{mL}$ and the reference range for serum serotonin was $70-270 \mathrm{ng} / \mathrm{mL}$. 


\subsection{Statistical Analysis}

Statistical analyses were performed using SPSS (version 25, IBM, SPSS Statistics, Armonk, NY, USA) and GraphPad Prism 5 (GraphPad Software, San Diego, CA, USA).

Statistically significant outliers were excluded using Gubb's test. Continuous variables were tested for normal distribution by using the Shapiro-Wilk test. Data are presented as mean \pm standard deviation if found to follow a Gaussian distribution, otherwise as median with interquartile range.

Variables following a Gaussian distribution were compared using a Student's $t$-test or ANOVA with Bonferroni correction, non-normally distributed continuous values were compared by using a Mann-Whitney U test or Kruskal-Wallis test with Dunn's correction. For the analysis of repeated measurements (all data in this case were non-parametric), the Friedman test with Bonferroni correction was applied.

Correlation analysis was performed using the Pearson correlation test for parametric data or by a Spearman test for non-parametric data.

A $p$-value less than 0.05 was considered statistically significant for all analyses except for the analysis of correlation. This analysis required correction by Bonferroni's method. This set the new statistically significant $p$-value at 0.0022 .

\section{Results}

\subsection{Patient Characteristics}

The average age across the STEMI group was $60.1 \pm 12.9$ years and $61.6 \pm 21.3$ years in the control group $(p=0.7002)$. The majority of the STEMI patients were male $(76.3 \%)$, compared to $46 \%$ in the control cohort, however, the difference was not statistically significant $(p=0.818)$. Serum creatinine, urea (BUN), or CRP did not differ between both groups (Table 1).

Table 1. Patient characteristics. ${ }^{\text {a }}$ Presented as median \pm interquartile range, ${ }^{b}$ presented as mean \pm standard deviation, ${ }^{\mathrm{c}}$ number of patients (with percentage based on the number of patients with a non-missing value for that characteristic), ${ }^{\mathrm{d}}$ based on Student's $t$-test for variables following a Gaussian distribution, ${ }^{\mathrm{e}}$ based on Mann-Whitney U test for non-parametric variables, ${ }^{\mathrm{f}}$ based on chi-squared test/Fisher's exact test as appropriate for categorical variables.

\begin{tabular}{|c|c|c|c|}
\hline & $\begin{array}{l}\text { STEMI } \\
(\mathrm{n}=38)\end{array}$ & $\begin{array}{l}\text { Control } \\
(n=50)\end{array}$ & $p$-Value \\
\hline \multicolumn{4}{|l|}{ Overall Characteristics } \\
\hline Age [Years] & $60.1 \pm 12.9^{b}$ & $61.6 \pm 21.3^{b}$ & $0.7002^{d}$ \\
\hline Sex [Male] & $29(76.3 \%)^{c}$ & $23(46 \%)^{c}$ & $0.818^{f}$ \\
\hline \multicolumn{4}{|l|}{ Laboratory Findings } \\
\hline $\begin{array}{l}\text { Serum Creatinine }[\mathrm{mg} / \mathrm{dL} \text {, } \\
\text { reference range } 0.51-0.95 \mathrm{mg} / \mathrm{dL}\end{array}$ & $1.0 \pm 0.2^{\mathrm{a}}$ & $0.9 \pm 0.5^{\mathrm{a}}$ & $0.3431^{\mathrm{e}}$ \\
\hline $\begin{array}{l}\text { Urea }(B U N)[\mathrm{mg} / \mathrm{dL} \text {, reference } \\
\text { range } 16.6-48.5 \mathrm{mg} / \mathrm{dL}]\end{array}$ & $32.0 \pm 13.0^{a}$ & $32.5 \pm 36.8^{a}$ & $0.9074^{\mathrm{e}}$ \\
\hline $\begin{array}{l}\text { C-reactive protein }(\mathrm{CRP})[\mathrm{mg} / \mathrm{L} \text {, } \\
\text { reference range }<5 \mathrm{mg} / \mathrm{L}]\end{array}$ & $9.0 \pm 42.0^{\mathrm{a}}$ & $24.1 \pm 72.4^{\mathrm{a}}$ & $0.3981^{\mathrm{e}}$ \\
\hline
\end{tabular}

The STEMI patients mostly featured a pronounced cardiovascular risk profile. Of them, $60.5 \%$ suffered from arterial hypertension, $50 \%$ from hypercholesterolemia, and $26.3 \%$ from diabetes mellitus. Furthermore, $39.5 \%$ were current smokers and $15.8 \%$ had quit smoking in recent years. The culprit lesion in most of our STEMI patients was either RCA $(44.7 \%)$ or LAD (47.4\%). The median left ventricular ejection fraction (LVEF) after myocardial infarction was $45.0 \%$ (Table 2). 
Table 2. Coronary artery disease (CAD) characteristics in the ST-elevation myocardial infarction (STEMI) cohort. a Presented as median \pm interquartile range, ${ }^{b}$ presented as mean \pm standard deviation, ${ }^{c}$ number of patients (with percentage based on the number of patients with a non-missing value for that characteristic. Hypercholesterolemia was defined as total cholesterol $>200 \mathrm{mg} / \mathrm{dL}$ or on medication. For creatine kinase (CK), creatine kinase myocardial band (CK-MB), myoglobin, troponin, and brain natriuretic peptide (BNP), the peak values within the first $24 \mathrm{~h}$ after myocardial infarction are listed.

\begin{tabular}{|c|c|c|c|c|}
\hline Cardiovascular Risk Profile & & & & \\
\hline Diabetes & & $10(26.3 \%)^{c}$ & HbA1c $[\%]$ & $5.8 \pm 1.3^{\mathrm{a}}$ \\
\hline \multirow[t]{2}{*}{ Hypercholesterolemia } & & $19(50 \%)^{c}$ & $\begin{array}{c}\text { total cholesterol } \\
{[\mathrm{mg} / \mathrm{dL}]}\end{array}$ & $180.0 \pm 41.5^{b}$ \\
\hline & & & $\begin{array}{c}\text { low density } \\
\text { lipoprotein (LDL) } \\
{[\mathrm{mg} / \mathrm{dL}]}\end{array}$ & $120 \pm 40^{b}$ \\
\hline Overweight & & $14(36.8 \%)^{\mathrm{c}}$ & BMI $\left[\mathrm{kg} / \mathrm{m}^{2}\right]$ & $28.6 \pm 5.05^{\mathrm{a}}$ \\
\hline Arterial Hypertension & & $23(60.5 \%)^{c}$ & & \\
\hline Positive Family History & & $13(34.2 \%)^{c}$ & & \\
\hline \multirow[t]{2}{*}{ Smoking } & current & $15(39.5 \%)^{c}$ & & \\
\hline & previous & $6(15.8 \%)^{c}$ & & \\
\hline \multicolumn{5}{|l|}{ CAD Characteristics } \\
\hline \multirow{3}{*}{$\begin{array}{c}\text { Number of Coronaries } \\
\text { Affected }\end{array}$} & 1 & $11(28.9 \%)^{c}$ & & \\
\hline & 2 & $14(36.8 \%)^{\mathrm{c}}$ & & \\
\hline & 3 & $13(34.2 \%)^{c}$ & & \\
\hline \multirow{3}{*}{ Culprit Lesion } & RCA & $17(44.7 \%)^{\mathrm{c}}$ & & \\
\hline & LAD & $18(47.4 \%)^{\mathrm{c}}$ & & \\
\hline & LCX & $3(7.9 \%)^{c}$ & & \\
\hline $\begin{array}{c}\text { CK Peak }[\mathrm{U} / \mathrm{L}, \text { reference } \\
\text { range }<170 \mathrm{U} / \mathrm{L}]\end{array}$ & & $740.0 \pm 2385.0^{a}$ & & \\
\hline $\begin{array}{c}\text { CK-MB Peak [U/L, reference } \\
\text { range }<24 \mathrm{U} / \mathrm{L}]\end{array}$ & & $85.0 \pm 251.0^{a}$ & & \\
\hline $\begin{array}{l}\text { Myoglobin Peak [ng/mL, } \\
\text { reference range 19-51 ng/mL] }\end{array}$ & & $181.0 \pm 734.5^{\mathrm{a}}$ & & \\
\hline $\begin{array}{c}\text { Troponin Peak }[\mathrm{ng} / \mathrm{L}, \text { reference } \\
\text { range }<14 \mathrm{ng} / \mathrm{L}]\end{array}$ & & $2226.5 \pm 4930.0^{a}$ & & \\
\hline $\begin{array}{c}\text { BNP Peak }[\mathrm{pg} / \mathrm{mL} \text {, reference } \\
\text { range }<125 \mathrm{pg} / \mathrm{mL}]\end{array}$ & & $1365.0 \pm 1976^{\mathrm{a}}$ & & \\
\hline $\begin{array}{l}\text { left ventricular ejection } \\
\text { fraction (LVEF) [\%] }\end{array}$ & & $45.0 \pm 10.0^{\mathrm{a}}$ & & \\
\hline
\end{tabular}

\subsection{Kinetics of Serum Serotonin}

Serum serotonin levels ranged between 21.3 and $325.3 \mathrm{ng} / \mathrm{mL}$, with a median of $114.2 \mathrm{ng} / \mathrm{mL}$ (IQR: 71.9-135.3). Median and interquartile range were within the reference range for serum serotonin levels (70-270 ng/mL).

The first samples were taken prior to coronary angiography $(\mathrm{t}=0)$ and subsequently 8,16 and $24 \mathrm{~h}$ later. We did not see any significant increase or decrease in serum serotonin levels during the observed $24 \mathrm{~h}$ interval. Moreover, all median values were within the reference range for serum serotonin ( $90.7 \mathrm{ng} / \mathrm{mL}, 108.0 \mathrm{ng} / \mathrm{mL}, 105.6 \mathrm{ng} / \mathrm{mL}, 87.6 \mathrm{ng} / \mathrm{mL})$. Compared to serum serotonin levels, the currently used biomarkers for myocardial damage, myoglobin, troponin, and CK, showed a significant increase after myocardial infarction and PCI (Figure 1). 

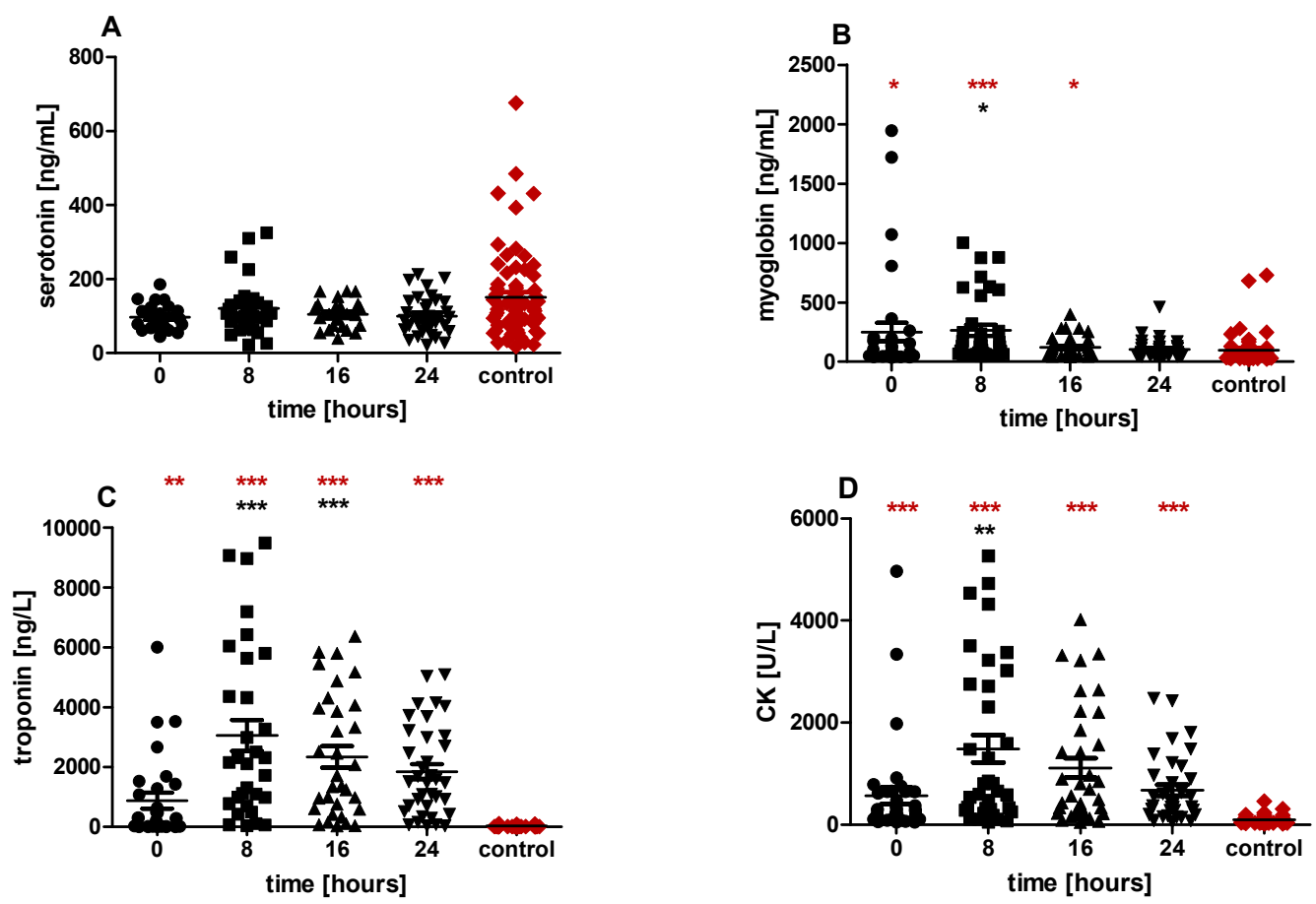

Figure 1. Analysis of serum samples prior to coronary angiography $(t=0)$ and 8,16 and $24 \mathrm{~h}$ after intervention in the STEMI group (depicted in black) and in an age-matched control group (depicted in red). Serum serotonin (A), myoglobin (B), troponin (C), and CK (D) were analyzed. After STEMI, serum serotonin showed no increase or decrease within the $24 \mathrm{~h}$ interval compared to the control group or compared to $t=0$ (A). Myoglobin, troponin, and CK showed a significant increase after coronary angiography compared to $\mathrm{t}=0$ and compared to the control group. ${ }^{*} p<0.05,{ }^{* *} p<0.01,{ }^{* * *} p<0.001$ compared to $\mathrm{t}=0,{ }^{*} p<0.05,{ }^{* *} p<0.01,{ }^{* * *} p<0.001$ compared to control group.

\subsection{Analysis of Thrombolysis in Myocardial Infarction (TIMI) Grade}

We analyzed the thrombolysis in myocardial infarction (TIMI) grade prior to and post coronary angiography. Whereas most patients presented a TIMI grade of 0 or 1 prior to coronary intervention, it was 2 to 3 in all of them post PCI, indicating successful recanalization of the diseased vessel. Serum serotonin levels did not differ between the TIMI grades (Figure 2).
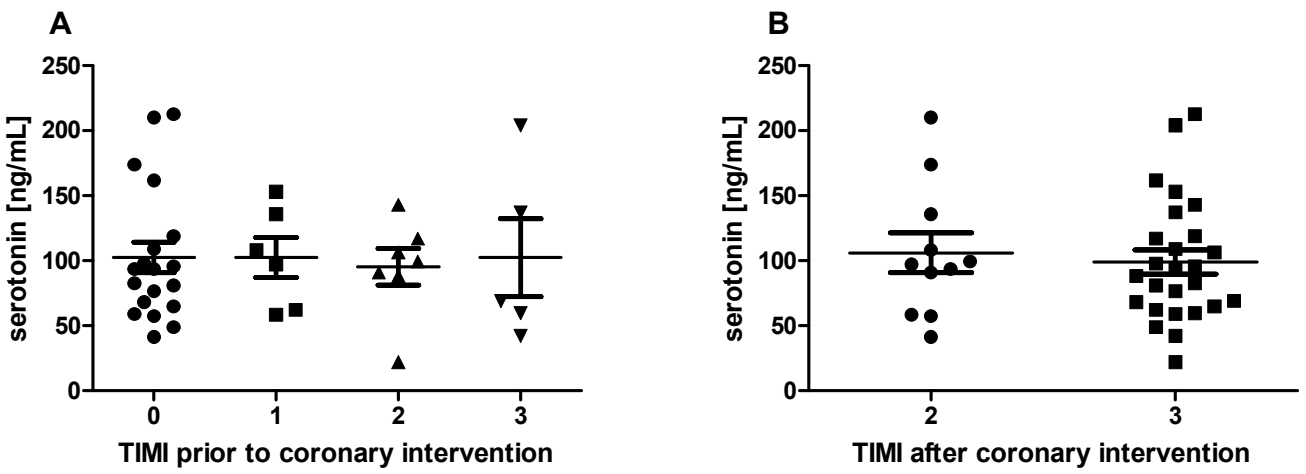

Figure 2. Serum serotonin levels according to a visual analysis of coronary angiography using the thrombolysis in myocardial infarction (TIMI) grade; TIMI prior to coronary intervention (A) and after coronary intervention $(\mathbf{B})$. 


\subsection{Ischemia/Reperfusion Injury}

Patients who were deemed to have suffered from I/R injury after PCI regarding the ECG analysis displayed no difference in mean serum serotonin levels in comparison to those deemed to have achieved adequate reperfusion $(109.1 \pm 84.08 \mathrm{pg} / \mathrm{mL}$ vs. $97.52 \pm 58.8 ; p=0.9663)$, Figure 3A.
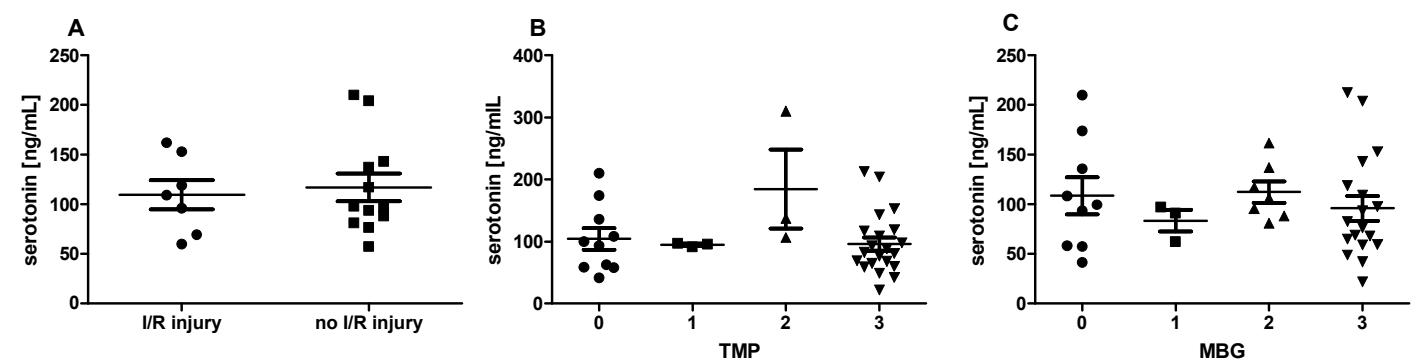

Figure 3. Serum serotonin and ischemia/reperfusion I/R injury. Serum serotonin levels did not differ between patients who suffered from I/R injury and those who did not. I/R injury was either assessed by ECG analysis (A) or by visual analysis of coronary angiography using the TIMI myocardial perfusion grade (TMP) (B) and the myocardial blush grade (MGB) (C).

The analysis of the TIMI myocardial perfusion grade (TMP) and the myocardial blush grade (MGB) did not show altered serum serotonin levels in patients with $\mathrm{I} / \mathrm{R}$ injury if assessed visually with these markers (Figure 2B,C).

Figure 4 demonstrates that the severity of disease and the outcome were not associated with serum serotonin levels. Neither the type of coronary artery disease (one-, two-, or three-vessel disease) nor the left ventricular ejection fraction (LVEF) were associated with different serum serotonin concentrations.
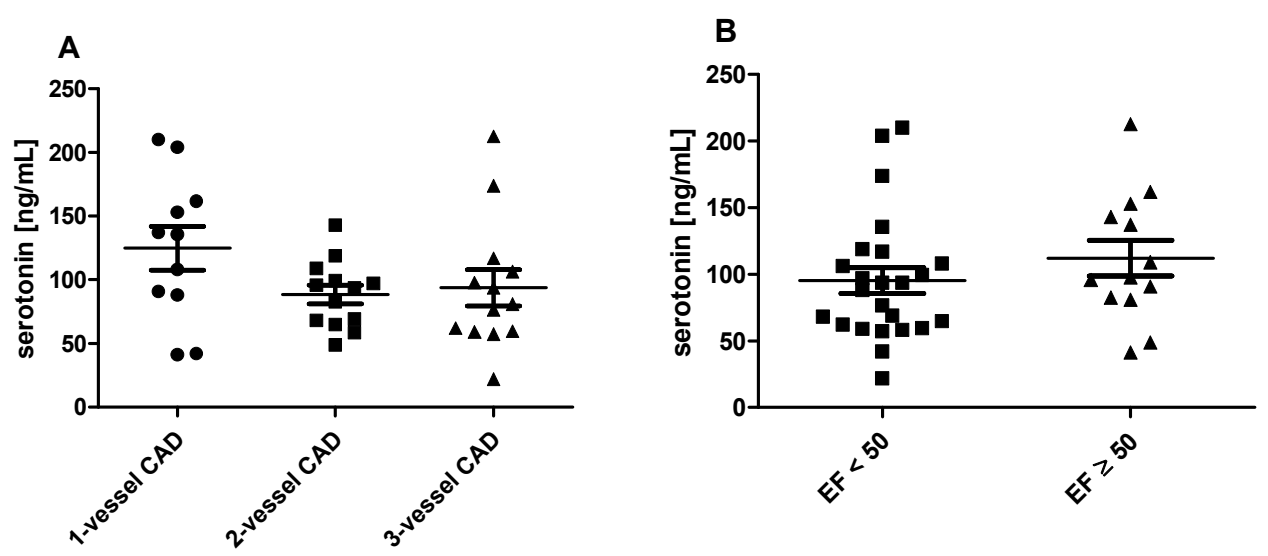

Figure 4. Neither the type of coronary artery disease (CAD) (A) nor the left ventricular ejection fraction (B) determined by echocardiography were associated with alterations in serum serotonin levels.

\subsection{Correlation Analysis}

After Bonferroni's correction for multiple comparisons (new significant $p$-value set at 0.0022, Table 3), none of the characteristics listed demonstrated a significant correlation with serum serotonin levels. 
Table 3. Correlation analysis.

\begin{tabular}{|c|c|c|}
\hline & $\mathbf{r}$ & $p$-Value \\
\hline \multicolumn{3}{|l|}{ Overall Characteristics } \\
\hline age & -0.4258 & 0.0086 \\
\hline $\operatorname{sex}$ & -0.025 & 0.880 \\
\hline \multicolumn{3}{|l|}{ Cardiovascular Risk Factors } \\
\hline diabetes & -0.071 & 0.673 \\
\hline $\mathrm{HbA1c}$ & -0.06591 & 0.7025 \\
\hline hypercholesterolemia & 0.006 & 0.972 \\
\hline total cholesterol & -0.03373 & 0.8452 \\
\hline LDL cholesterol & -0.01326 & 0.9388 \\
\hline overweight & 0.095 & 0.572 \\
\hline BMI & 0.1458 & 0.4034 \\
\hline arterial hypertension & -0.248 & 0.133 \\
\hline positive family history & 0.278 & 0.092 \\
\hline smoking & 0.007 & 0.965 \\
\hline \multicolumn{3}{|l|}{ CAD Characteristics } \\
\hline number of coronaries affected & -0.235 & 0.156 \\
\hline CK peak & 0.180 & 0.279 \\
\hline CK-MB peak & 0.065 & 0.703 \\
\hline myoglobin peak & 0.099 & 0.578 \\
\hline troponin peak & -0.116 & 0.542 \\
\hline proBNP peak & -0.300 & 0.071 \\
\hline LVEF & 0.421 & 0.009 \\
\hline \multicolumn{3}{|l|}{ Other Laboratory Findings } \\
\hline platelet count & -0.1124 & 0.5403 \\
\hline creatinine & 0.1662 & 0.3326 \\
\hline BUN & -0.1773 & 0.2938 \\
\hline CRP & -0.3023 & 0.0926 \\
\hline
\end{tabular}

\section{Discussion}

In this pilot study, we investigated for the first time if 5-HT serum levels are altered in patients with STEMI and if they are associated with the severity of myocardial damage, in order to evaluate it as a potentially novel biomarker for AMI and I/R injury.

Immediate restoration of blood flow by coronary angiography improves survival and outcome in patients with STEMI [3,4]. The death of cardiomyocytes during STEMI results from both necrosis and apoptosis. Troponins and CK-MB are routinely used in clinical practice and are validated biomarkers of cell lysis, necrosis, and overall myocardial damage to estimate infarct size $[6,35,36]$. However, the specificity of these markers is limited [7] and they can be elevated in acute myocardial injury of non-ischemic origin $[6,8,9]$. Moreover, troponins can be chronically raised in patients with congestive heart failure or chronic kidney disease [6,7] and CK and myoglobin can be altered in patients with rhabdomyolysis [37]. Therefore, there is need for additional, more specific, and more precise biomarkers.

In this pilot study, we assessed if serum 5-HT correlates with clinical variables and markers of cell lysis (e.g., CK, myoglobin, and cTNT) and further investigated whether it could predict I/R injury in STEMI patients after PCI. The hypothesis that 5-HT serum levels might be associated with the extent of myocardial damage after AMI was, on the one hand, based on previous studies reporting altered serotonin levels after myocardial infarction and, on the other hand, based on recent findings that that 5-HT aggravates I/R injury [12,22].

5-HT plays a crucial role in AMI. Ninety to ninety-five percent of 5-HT is stored in the dense granules of platelets, and released upon activation [13]. In AMI, the platelet-stimulating microenvironment 
and the thrombus formation in the coronaries lead to an activation of platelets with the subsequent local release of 5-HT [22]. The increased local 5-HT levels contribute, on the one hand, to enhanced recruitment and aggregation of platelets [13]. On the other hand, 5-HT, as a vasoactive substance, leads to the constriction of coronary smooth muscle cells, further worsening myocardial damage [23]. Consistent with this are findings from rat experiments revealing an increase in 5-HT concentrations in the heart tissue after myocardial infarction [23], representing enhanced platelet activation and aggregation. As a consequence of the release of platelet 5-HT in the coronary arteries, plasma 5-HT levels markedly increase after AMI in mice and humans [12,25]. Mauler et al. reported a significant increase in plasma 5-HT in mice within the first $24 \mathrm{~h}$ after LAD ligation [12]. In humans, this increase in plasma 5-HT could also be observed: Jin et al. studied 30 cases of AMI and compared them with 13 cases of unstable angina. They reported a rapid increase in plasma 5-HT within the first $24 \mathrm{~h}$ after AMI, compared to no alteration in the unstable angina group. Moreover, they found an association between the severity of AMI and plasma 5-HT levels [25]. As discussed by Brand and Anderson [38] and as we experienced in previous experiments, the accurate generation of plasma for the determination of 5-HT levels is delicate and easily prone to error. Plasma concentrations of 5-HT are very low under physiologic conditions [13] and any activation of platelets during the process of plasma generation needs to be strictly avoided. To ensure that, immediate and gentle processing of blood samples is necessary, which is not always possible in clinical practice. We therefore aimed to evaluate serum 5-HT as a potential biomarker, which is much easier to handle and less prone to error. However, we could neither find differences in serum serotonin levels between our STEMI cohort and the control group nor find any changes in 5-HT levels detectable within the $24 \mathrm{~h}$ study period in our collective.

A second objective of our pilot study was to examine whether serum 5-HT was suitable as a biomarker for I/R injury. As mentioned above, early reperfusion is mandatory in patients with STEMI to salvage myocardium and reduce infarct size. However, reperfusion itself might provoke additional injury, leading to increased infarct size and microvascular dysfunction [10,39]. This deleterious process of reperfusion is characterized by ionic imbalance [40-42] and excess formation of reactive oxygen species [41], both contributing to necrosis, apoptosis, and cell death [10]. All these processes lead to impaired myocardial blood flow, resulting in the no-reflow phenomenon, myocardial stunning, and reperfusion arrhythmias [10]. About 35\% of STEMI patients suffer from incomplete reperfusion due to severe I/R injury [43]. Currently, myocardial damage induced by $\mathrm{I} / \mathrm{R}$ injury cannot be monitored due to a current lack of specific biomarkers.

It is well established that 5-HT causes deleterious effects in I/R injury: In 1994, it was first demonstrated that administration of nexopamil, a combined $\mathrm{Ca}^{2+}$ and 5-HT antagonist, reduced myocardial damage in a pig model after LAD occlusion [44]. In 2014, Guner et al. showed that the administration of fluoxetine, a selective 5-HT reuptake inhibitor, prevented I/R injury after aortic surgery in rats [45]. It was claimed that 5-HT deteriorates I/R injury by enhancing oxidative stress caused by mitochondrial monoaminooxidase-A (MAO-A) activity during the process of 5-HT degradation [46]. Mauler et al. recently found that 5-HT aggravates myocardial I/R injury by aggravating neutrophil degranulation, and that I/R injury was accompanied by an elevation in 5-HT plasma levels [12]. Moreover, when $\mathrm{Tph}^{-/-}$mice (mice without peripheral serotonin) were subjected to myocardial ischemia with reperfusion, the infarct size was significantly reduced by about $35 \%$ compared to wildtype (WT) controls [12]. We therefore hypothesized that serum 5-HT levels might be associated with $\mathrm{I} / \mathrm{R}$ injury in our collective.

We used the comparison of ST-segment elevation in standard 12-lead ECG prior to and after PCI as a surrogate marker for I/R injury. Incomplete resolution of ST-segment elevation has been shown to be an indicator for $\mathrm{I} / \mathrm{R}$ injury and a prognostic marker for 90-day prognosis, death, development of heart failure, and shock $[30,31]$. Moreover, we additionally analyzed the visual markers TMP and MGB for the assessment of I/R injury: Impaired perfusion of the myocardium in coronary arteriography assessed by use of the TMP grade was described to be related to a higher risk of mortality [47]. Moreover, 
the outcome assessed by the MBG was also associated with mortality in patients with STEMI [34]. Contrary to our expectations, 5-HT serum levels did not correlate with I/R injury in our collective. We assume that the local release of 5-HT in the coronary vessels is too low to alter systemic serum 5-HT concentrations.

Our pilot study was limited by the relatively small sample size of patients with STEMI. It was clearly underpowered to identify small differences in serum 5-HT and its association with I/R injury. However, CK and cTnT, as established biomarkers for AMI, increased as expected, whereas serum 5-HT did not show any kinetics, indicating a lack of suitability of 5-HT as an appropriate biomarker.

Another strength of the study is that blood was drawn at four distinct time points after myocardial infarction. This allowed for a time course of 5-HT serum levels during AMI and again revealed that it is not suitable as a biomarker for the extent of myocardial damage or $\mathrm{I} / \mathrm{R}$ injury.

\section{Conclusions}

In conclusion, we have shown that 5-HT serum levels are not suitable as a biomarker in acute myocardial infarction. There was no alteration in serum serotonin levels after STEMI compared to an age-matched control cohort. We did not observe any timeline change within $24 \mathrm{~h}$ post PCI compared to before PCI. Moreover, the severity of coronary artery disease, the outcome of coronary angiography, the extent of ischemia/reperfusion injury, and the degree of heart failure were not associated with any alterations in 5-HT serum levels.

Author Contributions: M.R., M.H., D.D., and I.A. designed the study. R.L. collected STEMI serum samples, M.R. performed ELISA measurements. T.W. analyzed coronary angiographies and determined TIMI, TMB, and MBG. M.R., A.L., and D.D. set up the control cohort, M.R. performed ELISA measurements. N.S., L.H., C.v.z.M., C.B., and C.B.O. advised on study design or interpreted the data. M.R. wrote the first draft of the manuscript, supported by M.H. All authors critically revised the manuscript for important intellectual content. All authors have read and agreed to the published version of the manuscript.

Funding: Marina Rieder is funded by the IMM-PACT Program for Clinician Scientists, Department of Medicine II, Medical Center-University of Freiburg and Faculty of Medicine, University of Freiburg, funded by the Deutsche Forschungsgemeinschaft (DFG, German Research Foundation) -413517907: Achim Lother is funded by the Berta-Ottenstein Program for Advanced Clinician Scientists, Faculty of Medicine, University of Freiburg.

Conflicts of Interest: C.B.O. reports research support from the German Research Foundation and from the Faculty of Medicine, University of Freiburg; speaker honoraria from Bayer Vital GmbH; writing honoraria from Georg Thieme Verlag AG. All authors declared no relevant conflict of interests. All authors agreed to publish this manuscript.

\section{References}

1. GBD 2016 Risk Factors Collaborators. Global, regional, and national comparative risk assessment of 84 behavioural, environmental and occupational, and metabolic risks or clusters of risks, 1990-2016: A systematic analysis for the Global Burden of Disease Study 2016. Lancet Lond. Engl. 2017, 390, 1345-1422. [CrossRef]

2. Barquera, S.; Pedroza-Tobías, A.; Medina, C.; Hernández-Barrera, L.; Bibbins-Domingo, K.; Lozano, R.; Moran, A.E. Global Overview of the Epidemiology of Atherosclerotic Cardiovascular Disease. Arch. Med. Res. 2015, 46, 328-338. [CrossRef]

3. Stirrup, J.; Velasco, A.; Hage, F.G.; Reyes, E. Comparison of ESC and ACC/AHA guidelines for myocardial revascularization. J. Nucl. Cardiol. Off. Publ. Am. Soc. Nucl. Cardiol. 2017, 24, 1046-1053. [CrossRef]

4. Vogel, B.; Claessen, B.E.; Arnold, S.V.; Chan, D.; Cohen, D.J.; Giannitsis, E.; Gibson, C.M.; Goto, S.; Katus, H.A.; Kerneis, M.; et al. ST-Segment elevation myocardial infarction. Nat. Rev. Dis. Primer 2019, 5, 39. [CrossRef]

5. Tzimas, G.; Antiochos, P.; Monney, P.; Eeckhout, E.; Meier, D.; Fournier, S.; Harbaoui, B.; Muller, O.; Schläpfer, J. Atypical Electrocardiographic Presentations in Need of Primary Percutaneous Coronary Intervention. Am. J. Cardiol. 2019, 124, 1305-1314. [CrossRef] [PubMed]

6. Thygesen, K.; Alpert, J.S.; Jaffe, A.S.; Chaitman, B.R.; Bax, J.J.; Morrow, D.A.; White, H.D. Fourth Universal Definition of Myocardial Infarction (2018). J. Am. Coll. Cardiol. 2018, 72, 2231-2264. [CrossRef] [PubMed]

7. Ooi, D.S.; Isotalo, P.A.; Veinot, J.P. Correlation of Antemortem Serum Creatine Kinase, Creatine Kinase-MB, Troponin I, and Troponin T with Cardiac Pathology. Clin. Chem. 2000, 46, 338-344. [CrossRef] [PubMed] 
8. Sarkisian, L.; Saaby, L.; Poulsen, T.S.; Gerke, O.; Jangaard, N.; Hosbond, S.; Diederichsen, A.C.P.; Thygesen, K.; Mickley, H. Clinical Characteristics and Outcomes of Patients with Myocardial Infarction, Myocardial Injury, and Nonelevated Troponins. Am. J. Med. 2016, 129, 446.e5-446.e21. [CrossRef] [PubMed]

9. Sarkisian, L.; Saaby, L.; Poulsen, T.S.; Gerke, O.; Hosbond, S.; Jangaard, N.; Diederichsen, A.C.P.; Thygesen, K.; Mickley, H. Prognostic Impact of Myocardial Injury Related to Various Cardiac and Noncardiac Conditions. Am. J. Med. 2016, 129, 506-514.e1. [CrossRef] [PubMed]

10. Heusch, G.; Gersh, B.J. The pathophysiology of acute myocardial infarction and strategies of protection beyond reperfusion: A continual challenge. Eur. Heart J. 2017, 38, 774-784. [CrossRef]

11. Hausenloy, D.J.; Botker, H.E.; Engstrom, T.; Erlinge, D.; Heusch, G.; Ibanez, B.; Kloner, R.A.; Ovize, M.; Yellon, D.M.; Garcia-Dorado, D. Targeting reperfusion injury in patients with ST-Segment elevation myocardial infarction: Trials and tribulations. Eur. Heart J. 2017, 38, 935-941. [CrossRef] [PubMed]

12. Mauler, M.; Herr, N.; Schoenichen, C.; Witsch, T.; Marchini, T.; Härdtner, C.; Koentges, C.; Kienle, K.; Ollivier, V.; Schell, M.; et al. Platelet Serotonin Aggravates Myocardial Ischemia/Reperfusion Injury via Neutrophil Degranulation. Circulation 2019, 139, 918-931. [CrossRef]

13. Mohammad-Zadeh, L.F.; Moses, L.; Gwaltney-Brant, S.M. Serotonin: A review. J. Vet. Pharmacol. Ther. 2008, 31, 187-199. [CrossRef] [PubMed]

14. Chase, T.N.; Murphy, D.L. Serotonin and central nervous system function. Annu. Rev. Pharmacol. 1973, 13, 181-197. [CrossRef] [PubMed]

15. Gershon, M.D. 5-Hydroxytryptamine (serotonin) in the gastrointestinal tract. Curr. Opin. Endocrinol. Diabetes Obes. 2013, 20, 14-21. [CrossRef] [PubMed]

16. Vanhoutte, P.M.; Lüscher, T.F. Serotonin and the blood vessel wall. J. Hypertens. Suppl. Off. J. Int. Soc. Hypertens. 1986, 4, S29-S35.

17. Myers, J.H.; Mecca, T.E.; Webb, R.C. Direct and sensitizing effects of serotonin agonists and antagonists on vascular smooth muscle. J. Cardiovasc. Pharmacol. 1985, 7, S44-S48. [CrossRef]

18. Duerschmied, D.; Bode, C. The role of serotonin in haemostasis. Hamostaseologie 2009, 29, 356-359.

19. Shajib, M.S.; Khan, W.I. The role of serotonin and its receptors in activation of immune responses and inflammation. Acta Physiol. Oxf. Engl. 2015, 213, 561-574. [CrossRef]

20. Schoenichen, C.; Bode, C.; Duerschmied, D. Role of platelet serotonin in innate immune cell recruitment. Front. Biosci. Landmark Ed. 2019, 24, 514-526.

21. Mauler, M.; Bode, C.; Duerschmied, D. Platelet serotonin modulates immune functions. Hamostaseologie 2016, 36, 11-16. [CrossRef] [PubMed]

22. Shimizu, Y.; Minatoguchi, S.; Hashimoto, K.; Uno, Y.; Arai, M.; Wang, N.; Chen, X.; Lu, C.; Takemura, G.; Shimomura, M.; et al. The role of serotonin in ischemic cellular damage and the infarct size-Reducing effect of sarpogrelate, a 5-hydroxytryptamine-2 receptor blocker, in rabbit hearts. J. Am. Coll. Cardiol. 2002, 40, 1347-1355. [CrossRef]

23. Takano, S.; Hoshino, Y.; Li, L.; Matsuoka, I.; Ono, T.; Kimura, J. Dual roles of 5-hydroxytryptamine in ischemia-Reperfusion injury in isolated rat hearts. J. Cardiovasc. Pharmacol. Ther. 2004, 9, 43-50. [CrossRef]

24. Sauer, W.H.; Berlin, J.A.; Kimmel, S.E. Effect of antidepressants and their relative affinity for the serotonin transporter on the risk of myocardial infarction. Circulation 2003, 108, 32-36. [CrossRef] [PubMed]

25. Jin, L.; Yan, X.W.; Xu, S.H. Platelet functions in patients with acute myocardial infarction. Zhonghua Xin Xue Guan Bing Za Zhi 1989, 17, 275-278, 317.

26. Ko, Y.-G.; Jung, J.-H.; Park, S.; Choi, E.; Joung, B.; Hwang, K.-C.; Ha, J.-W.; Choi, D.; Jang, Y.; Chung, N.; et al. Inflammatory and vasoactive factors in the aspirate from the culprit coronary artery of patients with acute myocardial infarction. Int. J. Cardiol. 2006, 112, 66-71. [CrossRef]

27. Silber, S. [Evidence-Based management of ST-Segment elevation myocardial infarction (STEMI). Latest guidelines of the European Society of Cardiology (ESC) 2010]. Herz 2010, 35, 558-564. [CrossRef]

28. Roy, S.S.; Abu Azam, S.T.M.; Khalequzzaman, M.; Ullah, M.; Arifur Rahman, M. GRACE and TIMI risk scores in predicting the angiographic severity of non-ST elevation acute coronary syndrome. Indian Heart J. 2018, 70, S250-S253. [CrossRef]

29. De Roeck, L.; Vandamme, S.; Everaert, B.R.; Hoymans, V.; Haine, S.; Vandendriessche, T.; Bosmans, J.; Ronsyn, M.W.; Miljoen, H.; Van Berendoncks, A.; et al. Adiponectin and ischemia-Reperfusion injury in ST segment elevation myocardial infarction. Eur. Heart J. Acute Cardiovasc. Care 2016, 5, 71-76. [CrossRef] 
30. Feldman, L.J.; Coste, P.; Furber, A.; Dupouy, P.; Slama, M.S.; Monassier, J.-P.; Tron, C.; Lafont, A.; Faraggi, M.; Le Guludec, D.; et al. Incomplete resolution of ST-Segment elevation is a marker of transient microcirculatory dysfunction after stenting for acute myocardial infarction. Circulation 2003, 107, 2684-2689. [CrossRef]

31. Buller, C.E.; Fu, Y.; Mahaffey, K.W.; Todaro, T.G.; Adams, P.; Westerhout, C.M.; White, H.D.; van 't Hof, A.W.J.; Van de Werf, F.J.; Wagner, G.S.; et al. ST-Segment recovery and outcome after primary percutaneous coronary intervention for ST-Elevation myocardial infarction: Insights from the Assessment of Pexelizumab in Acute Myocardial Infarction (APEX-AMI) trial. Circulation 2008, 118, 1335-1346. [CrossRef] [PubMed]

32. Ottani, F.; Latini, R.; Staszewsky, L.; La Vecchia, L.; Locuratolo, N.; Sicuro, M.; Masson, S.; Barlera, S.; Milani, V.; Lombardi, M.; et al. Cyclosporine A in Reperfused Myocardial Infarction: The Multicenter, Controlled, Open-Label CYCLE Trial. J. Am. Coll. Cardiol. 2016, 67, 365-374. [CrossRef] [PubMed]

33. Appleby, M.A.; Angeja, B.G.; Dauterman, K.; Gibson, C.M. Angiographic assessment of myocardial perfusion: TIMI myocardial perfusion (TMP) grading system. Heart Br. Card. Soc. 2001, 86, 485-486. [CrossRef] [PubMed]

34. Ng, V.G.; Lansky, A.J.; Toro, S.; Parise, H.; Cristea, E.; Mehran, R.; Stone, G.W. Prognostic utility of myocardial blush grade after PCI in patients with NSTE-ACS: Analysis from the ACUITY trial. Catheter. Cardiovasc. Interv. 2016, 88, 215-224. [CrossRef] [PubMed]

35. Antman, E.M. The Introduction and Clinical Use of Cardiac-Specific Troponin Assays. Clin. Pharmacol. Ther. 2018, 103, 31-33. [CrossRef]

36. Wang, X.-Y.; Zhang, F.; Zhang, C.; Zheng, L.-R.; Yang, J. The Biomarkers for Acute Myocardial Infarction and Heart Failure. BioMed Res. Int. 2020, 2020, 2018035. [CrossRef]

37. Stahl, K.; Rastelli, E.; Schoser, B. A systematic review on the definition of rhabdomyolysis. J. Neurol. 2019, 267, 1-6. [CrossRef]

38. Brand, T.; Anderson, G.M. The measurement of platelet-poor plasma serotonin: A systematic review of prior reports and recommendations for improved analysis. Clin. Chem. 2011, 57, 1376-1386. [CrossRef]

39. Bolli, R. Myocardial "stunning" in man. Circulation 1992, 86, 1671-1691. [CrossRef]

40. Tani, M.; Neely, J.R. Role of intracellular Na+ in Ca2+ overload and depressed recovery of ventricular function of reperfused ischemic rat hearts. Possible involvement of $\mathrm{H}+-\mathrm{Na}+$ and $\mathrm{Na}+\mathrm{Ca} 2+$ exchange. Circ. Res. 1989, 65, 1045-1056. [CrossRef]

41. Schlüter, K.D.; Jakob, G.; Ruiz-Meana, M.; Garcia-Dorado, D.; Piper, H.M. Protection of reoxygenated cardiomyocytes against osmotic fragility by nitric oxide donors. Am. J. Physiol. 1996, 271, H428-H434. [CrossRef] [PubMed]

42. Piper, H.M.; Meuter, K.; Schäfer, C. Cellular mechanisms of ischemia-reperfusion injury. Ann. Thorac. Surg. 2003, 75, S644-S648. [CrossRef]

43. Niccoli, G.; Burzotta, F.; Galiuto, L.; Crea, F. Myocardial no-Reflow in humans. J. Am. Coll. Cardiol. 2009, 54, 281-292. [CrossRef]

44. Hohlfeld, T.; Braun, M.; Strobach, H.; Schrör, K. Protection of reperfused ischemic pig myocardium by nexopamil, a new combined Ca2+ and serotonin antagonist. J. Cardiovasc. Pharmacol. 1994, 23, 922-931. [CrossRef] [PubMed]

45. Guner, I.; Yaman, M.O.; Aksu, U.; Uzun, D.; Erman, H.; Inceli, M.; Gelisgen, R.; Yelmen, N.; Uzun, H.; Sahin, G. The effect of fluoxetine on ischemia-Reperfusion after aortic surgery in a rat model. J. Surg. Res. 2014, 189, 96-105. [CrossRef] [PubMed]

46. Pascale, B.; Oxana, K.; Emanuela, M.; Claudie, C.; Daniele, B.; Laura, R.; Marie-Helene, S.; Silvia, N.; Wilson, C.; Nathalie, L.; et al. Oxidative Stress by Monoamine Oxidase Mediates Receptor-Independent Cardiomyocyte Apoptosis by Serotonin and Postischemic Myocardial Injury. Circulation 2005, 112, 3297-3305. [CrossRef]

47. Gibson, C.M.; Cannon, C.P.; Murphy, S.A.; Ryan, K.A.; Mesley, R.; Marble, S.J.; McCabe, C.H.; Van De Werf, F.; Braunwald, E. Relationship of TIMI myocardial perfusion grade to mortality after administration of thrombolytic drugs. Circulation 2000, 101, 125-130. [CrossRef] [PubMed]

(C) 2020 by the authors. Licensee MDPI, Basel, Switzerland. This article is an open access article distributed under the terms and conditions of the Creative Commons Attribution (CC BY) license (http://creativecommons.org/licenses/by/4.0/). 